\title{
Innovation, Dynamics of Competition and Market Dynamics
}

\author{
Hans W. Gottinger \\ STRATEC Munich Germany
}

\begin{abstract}
Largely from the perspective of network economics we look into a specific range of economic studies on competition, innovation and technological change with a view to relating theories, models and ideas on how best to analyze the impact of innovation and market dynamics on scale and scope of network industries. Innovation has a major network inducing effect, so has competition. Competition in this context always carries dynamic features and is intrinsically linked to games of strategy. Our review focuses on both the interaction of competition and innovation and discusses prevailing models of innovation and studies that fall within other traditions such as Schumpeterian economics.
\end{abstract}

Keywords: Innovation, Competition, Network Industry, Dynamic Markets, Schumpeterian Economics

\section{INTRODUCTION}

Ever since Schumpeter (1942) was suggesting that large private organizations (firms) would count for the majority of product/process innovations in a dynamic (Schumpeterian) economy the discussion continues across industries, market structures and competitive scale whether and to which extent large companies as compared to small and mid-sized firms (SMFs) will continuously generate a larger bulk of innovations (in terms of revenues or profits).

An investigation would need to clarify how to capture and measure innovation in specific industries and how to identify success in the market context. Further what are the underlying diverse explanatory factors (variables) that incentivise firms to engage in serial innovations and result in structural growth of the company? Thus it carries a standardized operational measurement, an incentive and performance problem within an organization.

The two major hypotheses linked to Schumpeter's exploration would be:

1. Do most innovations increase more than proportionately with firm size?

2. Does innovation increase with market concentration?

With regard to measurement there are no standardized measures of innovation that clearly allow definable interindustry or even interfirm comparison except for certain kinds of product innovations that are technically identifiable such as performance in, say, semiconductors or new chemical entities in pharmaceuticals, and sometimes left for economic proxies such as welfare or quality changes.

For process innovations, productivity changes as in factor productivity in the respective organisation could be an appropriate measure. Further, patent data (counts) have been used frequently as approximations of innovative activity of firms in some industries -- though more relevant in some (pharmaceuticals) than in others (software). However, the economic value of patent counts is highly heterogeneous. 
The diversity of organizations, and across industries, make it challenging to specify econometric models in which the major explanatory variables could reasonably explain the level of innovative activity of the organization as a dependent variable. For example, some variables expected to influence process innovation may have no impact on product innovation and vice versa. Also the importance of these variables may vary on innovative activities across types of industries.

For private organisations such as firms what has been of key interest is the relationship of firm size and market structure. Schumpeter was impressed by the qualitative difference between innovative activities of SMFs and large modern corporations with established R\&D laboratories. It has been suggested in industrial economics since then, as a hypothesis, that there is a positive effect of firm size on innovative activity.

With firms the arguments for the positive relationship have been given by:

i. $\quad$ Larger firms are better able to access financial assets for risky R\&D projects;

ii. Larger firms may have already built up a record of successful R\&D projects that feeds into continuous research activities (cumulative innovation),

iii. In some industries there are scale economies in R\&D,

iv. Larger firms are more likely to be diversified, and because of synergies R\&D is more productive in large firms in view of complementarities and R\&D covering other business activities.

A contrarian view was built on observations that as firms grow larger there appears a loss of managerial control impacting R\&D performance negatively. Also individual incentives of researchers could suffer because of losing identification with the outcome -- what Schumpeter himself considered as the hazard of bureaucratization of inventive activity.

Empirical studies over the past fifty years, as cross-section analyses or regression type studies have produced mixed results at best, that is neither strongly confirming nor denying the relationship across a fairly broad section of industries. Up to the 1990s in a review of the literature, Cohen and Levin (1989, p.1069) mention: The most notable feature of this considerable body of empirical research on the relationship between firm size and innovation is its inconclusiveness".

They explain this with the experimental design of the industry samples and the sample selection biases.

However, in areas of high-tech industries including ICT, advanced industrial technologies and pharmaceuticals gaining a higher share of industry compositions in

OECD countries it appears that very small firms (startups) and very large firms were more $R \& D$ intensive as the ratio of $R \& D$ expenditures to product sales than firms of intermediate size in respective industries (Scherer, 1984,1992).

For high-tech industries with a global focus innovation by itself is a strategic choice and 'imperative' - according to the CEO of General Electric(GE) Jeff Immelt. Growth of the firm and innovation are intimately related. For example, GE constantly evolves its product/service portfolio to drive growth despite its large size and already significant presence in major markets. It encourages its business units to take an expansive view of its markets to pursue growth opportunities. This continual questing and drive toward innovation lies behind its strategic positioning. In such a scenario input variables are dominated by research resources 
and the output by some innovation index. This is corroborated by strong rivalry positions of oligopolistic firms as reflected by technological racing in respective industries (Gottinger, 2006, Chaps.1-3). Early on Scherer (1984, Chap.9) suggested that SMFs with high entrepreneurial input may be a more important source of innovation in the U.S. But for parts of Europe, in particular, Germany, this is matched by the charateristics of firms as 'hidden champions' although some of them would be considered large with more than USD 1 billion of annual revenue (Kucher, 2009).

Thus for firms in high-tech industries continuous innovation is the name of the game as competition in innovation drives the outcomes in growth, welfare changes and survival.

Without it structural growth in markets would not be possible whether in product technologies, services or operational performance. Innovation based firm growth would be a key indicator for a firm's sustainable future.

After resolving the issue how and why large firms are actively engaged in innovative activity an implicated next step could be how they continue to be innovative organisations. Under the presumption that large firms became 'large' because of 'growing through innovation' there is the question how they keep on being innovative for their lifetime.

Through studies of innovation in industrial organizations we learn that roughly two-third of innovations are of the product improvement type while one-third is of the process innovation type (cost reducing or productivity enhancing). We make use of this observation by assigning the first kind to private organizations (industrial firms) while the second to a public service centered organization, designed and regulated as such.

\section{COMPETITION, MARKET STRUCTURE AND INNOVATION}

We focus here on some key results from behavioral economic models in industrial organization( IO) that leave footprints for exploring the innovation drive and capability of firms in particular industry settings.

In characterizing and portraying the internal economy of large firms R. Radner (1986, p.5) has this to say on stakeholder analysis:

"[T]here are many 'players'in the firm's internal economy: shareholders, directors, managers and workers ... These different players typically have at least partially divergent interests; hence the difficulty of imputing to the firm a single objective. Among the objectives of the several players in the firm are profits, growth, monetary compensation for managers and workers, quality of work, perquisites, and status. In addition, in the pursuit of these objectives, the different players may have different attitudes toward risk."

But to satisfy and justify overwhelmingly and sustainably all the diverse interests it would be ongoing innovation and increasing returns to scale.

A long-standing question in the economics of technological change has been the nature of the relationship between market structure and innovation.

The relationship between concentration of an industry and its rate of technological innovation is complex. Market structure may have an impact on the rate of innovation, but innovation is also an important factor that shapes market structure. In fact, it is necessary to recognize that the relationship between concentration and innovation is not a causal one: both are the 
endogenous outcomes of the operation of market forces and exogenous factors such as the nature of demand, technological opportunity, the conditions governing use, and some chance.

The classical point of departure in the economic analysis of the relationship between static market structure (i.e. concentration) and innovation is the work by Arrow (1962). Arrow considers the case where a cost-reducing innovation is exogenously available and investigates firms' willingness to pay for the innovation under different market structures. For a drastic innovation, Arrow's analysis shows that a firm that is already a monopolist would have lower incentives to innovate than a firm that is currently in a perfectly competitive environment, essentially because it would have the lower profit incentive.

On the other hand, innovation is certainly an important factor that affects market structure: innovation is a means by which a firm tries to escape the constraints imposed by competition. Studies in the Schumpeterian tradition have emphasized the importance of ex-post market power for firms' incentives to innovate. Some degree of market power is necessary for a firm to cover its R\&D outlays: dynamic and static efficiency are somehow conflicting. This is a theme that has been well developed in the recent literature on endogenous economic growth.

The industrial organization literature has studied the relationship between concentration and innovation in firms' rivalry positions. If there are exogenous entry barriers, an increase in the number of firms causes each firm to spend less on R\&D in equilibrium, however total R\&D expenditure increases with the number of firms. When entry is considered to be endogenous, one would observe more innovation in those industries that are characterized by a higher degree of monopoly power, although no causality should be imputed to this relationship.

Some models consider the relationship between product market structure (i.e. concentration) and innovation. In the context of models where firms race to innovate another interesting question concerns the relationship between the number of firms that are part of the race and the pace of technological advance.

These are racing models of innovation where $R \& D$ expenditures are committed upfront (that is, the probability of success depends on the scale of the R\&D activity) and shows that increasing the number of firms reduces the expected date of invention.

One class of models consider a setting where firms can vary the research intensity but does not assume that the rate of expenditure is constant over time. Instead, firms may adjust R\&D intensity in response to elapsed time and rival progress. Then in this setting, when imitation is not possible, an increase in the number of firms increases the equilibrium rate of investment for each firm and decreases the expected time of innovation. When there is no full patent protection, the relationship is ambiguous and depends on the relative payoffs to the innovator and the imitators.

\section{Dominance}

In many advanced industries characterized by long-term market dynamics competition may take the form of competition for the market rather than competition in the market. In these markets the issue is not whether more or less concentration is associated with faster technological progress but whether market dynamics would be characterized by persistent dominance of the incumbent leader or by action-reaction whereby incumbents are overtaken by some rivals whose incumbency is itself of short duration. The dynamic evolution of market structure depends on both abilities and incentives of the incumbent and the rivals to innovate. Game theoretical models in industrial organization are well suited to analyze the incentives 
underlying R\&D investments and the resulting evolution of market structure. If we focus on economic incentives, and set aside differences in R\&D abilities, persistence of monopoly or action-reaction can be related to the different profit incentive and competitive threat faced by the leader and the follower(s).

The profit of a successful incumbent who innovates is that of a monopolist firm, whereas if it were the entrant to innovate each firm would get the profit of a duopolist. Hence, the competitive threat of the incumbent can be measured as the difference between the profit of a monopolist firm and the profit of a duopolist firm. The incumbent's competitive threat, instead, is simply equal to the profit of a duopolist. This implies that the incumbent would have more incentives to innovate (i.e. the larger competitive threat) if, as it is normally the case, the profit of a monopolist is greater than the combined profits of two duopolists.

For minor innovations, the industry leader will typically be the innovator, whether or not imitation and licensing are feasible. For markets where patent protection is strong, it is likely that the major innovations will be made by industry leaders. But if imitation is easy, industry followers or entrants will make the major discoveries. Racing models show that when the first innovator captures a sufficiently high share of the post innovation market, then the incumbent firm invests less on a given project than does the potential entrant. This is because the incumbent has less incentive than the challenger to shorten the period of its incumbency.

Market dynamics have also been investigated in models that consider a sequence of innovations. They consider a sequence of drastic innovations and show that market dynamics are characterized by a process that resembles Schumpeter's process of creative destruction: the incumbent invests less than each challenger in each stage. In comparing market dynamics under Bertrand and Cournot competition one finds that when the product market is very competitive then there is increasing dominance, but when it is not very competitive there is action-reaction. When innovation is drastic, then market dynamics are characterized by increasing dominance. The differences in the results obtained in industry models can be ascribed to the different roles that the profit incentive and the competitive threat play in innovation racing on rivalry. In a deterministic model the incentive to pre-empt (larger for the incumbent) dominates the firms' decision. When success is stochastic, however, the threat from the rival innovating is less acute. In the case of drastic innovations, the competitive threat is the same for both firms and it is the profit incentive (which is larger for challengers), next to diverse non-monetary incentives, that determines the level of R\&D investments. The relevance of the profit incentive extends to the case for some non-drastic innovation. Also even for large private enterprises the availability of venture capital, externally or internally, could provide an added incentive for facilitating continuous innovation (Lerner, 2012).

\section{Competition Intensity and Innovation}

Market structure is often associated with the concept of competitiveness: usually, a high level of concentration in an industry is interpreted as weak competition. This view is based on a symmetric Cournot model, where price-cost margins are higher as the number of firms increases. However, it is preferable to disentangle the notions of market structure and toughness of price competition as, among others, in Sutton (1998).

In a simple world with homogeneous firms, toughness of price competition can be considered as being related to the level of price-cost margins given any level of concentration. Hence, a differentiated Bertrand market would be considered to be more competitive than a differentiated Cournot market because price-cost margins would be lower in the former, for 
any level of concentration. As a result, more competitive markets may allow fewer firms to profitably survive.

When intensity of competition is low it is the follower that would be the next innovator, whereas when intensity of competition is large, it is the current technological leader that is likely to innovate. When it is the follower that innovates, tougher competition implies lower profits and hence lower incentives to innovate. However, when it is the current leader to innovate, an increase of toughness of price competition would further increase the profits related to his technological leadership and hence would increase the value of innovation for the firm. Hence, the relationship between toughness of price competition and innovation would be inversely-shaped. (Aghion and Griffith, 2005).

\section{SOURCES OF INNOVATION AND COMPETITION}

It has been only recently, mainly over the last four decades that the economic forces behind technological innovation have started to be investigated in more detail within modern economics. As a result, a wide variety of theories and models, sometimes very diverse in spirit, describing the economics of innovation are now available. All these theories share the common aim of providing a conceptual foundation for understanding how innovation affects the economy, how economic forces affect the emergence of technological changes, and the decision-making processes through which technological innovation occurs.

Traditional models of innovation focus on the study of firms' incentives to invest resources in Research and Development (R\&D) activities. Game-theoretical models (GTMs) developed in industrial organization have investigated firms' R\&D decisions in strategic environments (Gottinger, 2006).

GTMs in networks (Easley and Kleinfeld, 2010) - being genuinely competitive - suggest that there are two main forces that underlie firms' investment in R\&D: the search for higher profits and the threat posed by falling behind potential innovating rivals. They study these forces in a variety of market situations and address issues such as the interplay between innovation and market structure, the dynamics of competition and the nature of the relationship between intensity of competition and innovation.

These models provide a rich picture of what the plausible strategies and industry equilibria in dynamic markets can be. However, general predictions, that can be considered appropriate across all situations and industries, are scarce. On one hand, this is a result that seems to stress the lack of predictive power of these models, i.e. (almost) everything can be rationalized; on the other hand, however, the variety of results seems well to fit with the variety of observed behaviors and 'equilibria'. There is no general model that can uncritically be applied to any case: they have to be adapted to specific market situations.

Despite the absence of general results, these models are certainly useful tools to understand firms' incentives to invest in R\&D activities in strategic environments and to suggest what main factors may be central in shaping the nature of dynamic competition. For instance, these models suggest that: in order to understand R\&D investments it is necessary to understand how innovation may affect profits both of successful and unsuccessful innovators. One perspective captures the idea that firms want to innovate to increase their profits, another that firms want to innovate to maintain competitiveness.

The relationship between concentration of an industry and its rate of technological innovation is certainly complex and in general not a causal one: both should be thought of as the outcomes 
of the operation of market forces and exogenous factors such as the nature of demand, technological opportunity and specific industry related conditions.

Dynamic competition may be characterized by persistent dominance of the incumbent leader or by action-reaction whereby incumbents are overtaken by a rival whose incumbency itself could then be short-lived. The nature of market dynamics depends on a number of factors, such as the type of innovation, i.e. drastic or non-drastic, the uncertainties involved in $R \& D$ activities, the nature of patent protection and of knowledge spillovers, the intensity of product market competition, among others.

When the relationship between competition and innovation is investigated, it is necessary to be clear what the notion of intensity of competition describes and how this relates to market structure. Indeed a market where competition is tougher may be more concentrated simply because inefficient firms cannot survive. There may be trade-off between the intensity of static competition and innovation. In general, the relationship between intensity of competition and innovation need not be monotonic at all.

Endogeneous growth models suggest that innovation, resulting from intentional R\&D investments by profit-seeking firms or simply by unintentional learning-by-doing, is a fundamental driver of economic growth in the long run.

Early endogenous growth models stressed the importance of ex-post rents for innovation: competition would have a detrimental effect on innovation by decreasing the rents that an innovator would be able to gain. More recent models have emphasized another mechanism by which competition affects innovation: tougher competition may increase the incentives of firms to innovate in order to escape from fierce competition (see Tirole, 1988, Chapters 8-10; Aghion and Griffith, 2005). More recent studies suggest that the relationship between competition and innovation may not well be monotonic and that instead, one should expect an inverse-shaped relationship: when competition is low, an increase in competition would foster innovation; the reverse would happen when competition is fierce.

The result that competition may be conducive to innovation is also obtained in studies where the traditional behavioral assumption of profit-maximizing firms is relaxed. When principalagent considerations are introduced to explain managers' behaviors, another mechanism by which competition may favor innovation is suggested: the speed of innovation may be retarded by the slack of managers who tend to avoid private costs associated with innovation. When competition intensifies, the higher threat of bankruptcy may force managers to speed up the process at which new ideas are adopted. Hence, competition may be conducive to faster rates of innovation.

The evolutionary approach to the study of innovation has been developed on very different methodological basis than those underlying traditional economic models of innovation. In particular, we observe the rejection of the modeling assumptions of rationality and equilibrium that are fundamental to the traditional approach.

Evolutionary economics looks from the outset at dynamic processes. In particular, it is associated with the use of analogies from evolutionary biology to explain economic growth and the process of competition. Thus the cornerstones of an evolutionary analysis of competition and innovation are variety, selection and imitation (Jacquemin, 1987, Chaps 2, 3).

At a basic level, using Darwinian analogies, we can begin to appreciate the role of the market in selecting the more fit firms (efficient and profitable), products and techniques at the expense of 
less fit firms. In addition to this effect, we would expect to see imitation of winning ideas by those whose survival is otherwise threatened (although this is limited by the tacit nature of knowledge).

Inherent in this model of competition is the association between competition, experimentation and variety. A variety of experiments allows, through the process of selection, far greater economic progress than would be available through uniform optimization.

The economic development and innovation can be seen as a combined effect of selection (via competition) from a variety of competing routines and practices as well as the more endogenous process of agents seeking improved routines and practices. While the latter is certainly incorporated, if treated somewhat differently, under the mainstream neoclassical approach, the emphasis on selection from variety seems an important addition to this approach.

This suggests that models found in other branches of economics might miss something important when they analyze dynamics with reference to homogenous profit-maximizing firms: namely the benefits of selection from heterogeneity in capabilities and innovative experimentation.

\section{COMPETITION FOR NETWORK INDUSTRIES}

Product market competition can be understood as competition between firms in the supply of existing products. This competition can be conceptualized as the rivalry between firms in terms of marketing, and notably pricing, of their products taking as given the characteristics of products (including production processes and costs). In markets that are considered relatively 'static', product market competition is the main channel through which the competitive process takes place.

Competition in innovation or 'innovative competition' (Fisher et al., 1983, 38) can be understood as the competition between firms to develop new products and production processes; this competition is often associated with the ideas of a competitive threat from innovation. Two firms are competing in innovation if they are undertaking (uncoordinated) innovative activity that can be identified with the prospect of introduction of products or services that will compete in the future. This innovative activity could be investment in $R \& D$ or less formalized activity such as product improvement through a process of learning-by-doing. Where two firms are competing in innovation, we expect their decisions regarding innovative strategy to be influenced significantly by the innovative strategies employed by rival firms. Failure to innovate successfully will lead not just to loss of potential profit but also risk falling behind innovative rivals (Brenner, 1987, Chap. 3).

Traditional industrial economics. As covered in essays by George Stigler (1968), also makes use of the terminology of 'static' and 'dynamic' competition. Along the same lines as above, the static dimension of competition is usually related to price competition, which takes place given the set of products or services that are marketed by firms. Dynamic competition, on the other hand, refers to the process whereby new and improved products, services and production processes are introduced. However, in the context of 'innovation and competition' we consider it more appropriate to use the terminology of 'product market competition' and 'competition in innovation' as this is more specific and more conducive to the development of applied competition analysis and policy. 


\section{Winner-takes-all markets}

Industrial organization models, and the review of studies of network industries, suggest that competitive interaction in innovative activities may take different forms according to the structure of payoffs of innovative activities to 'winners' and 'losers'.

In some organization models, and the review of studies of network industries, suggest that competitive interaction in innovative activities may take different forms according to the structure of payoffs of innovative activities to 'winners' and 'losers'.

In the first case, competition in innovation may be the essential, or at the limit the only dimension of the competitive process, i.e. winner-takes-all markets. Persistence of monopoly may be observed in a winner-takes-all market, but provided that competition in innovation is effective, this does not necessarily imply that competitive forces are muted. On the other hand, in these markets, competition in innovation is the area where the current dominant firm may be more likely to abuse its dominance (since, by definition, such markets are not conducive to sustained product market competition).

These considerations suggest that it is useful to distinguish between different economic environments, according to the relative importance of competition in innovation and competition at the product market level that can be expected in the market. The literature on network industries is particularly useful in explaining why a market may exhibit winner-takesall properties.

\section{Network Effects}

Network effects may be an important factor in determining the competitive environment. A (positive) direct network externality exists when the demand for a service increases by an extra unit. In order for this effect to be 'direct' the reason for the increase in demand must come directly from the additional consumption of the service in question, without need for a strategic response by suppliers in the same or related market. For example, the demand for public telephony services (i.e. the demand for subscriptions to networks) may increase as more users consume this product (e.g. enter into subscription agreements with public network operators) simply because more users allow a greater number of potential connections to be made of the network.

By contrast, a (positive) indirect network externality exists where the demand for a service supplied in one relevant market has a significant effect on supply of another product (typically in a different relevant market) such that this in turn increases demand in the first relevant market.

An example of indirect network effects is that of computer software for a particular operating system platform. An increase in consumption in the market for supply of operating systems is likely to bring benefits to the markets for supply of compatible software, by expanding the market such that a greater variety of software is offered or the unit price decreases (since fixed costs of software development can be spread over a greater number of potential buyers). In turn, the benefits to the software markets render the same operating system more valuable, and thus increase demand for it. But the effect is indirect because it relies on a strategic response of software suppliers to the increase in the consumption of operating systems.

\section{Horizontal and Vertical Innovation}

The study of industrial organization and endogenous growth models suggests that the distinction between 'horizontal' and 'vertical' innovation may be useful. Horizontal innovation 
entails the discovery of a new product which, setting aside price considerations, is considered better than existing products only by some users (or for some uses). By contrast, vertical innovation entails the discovery of a new product which, setting aside price considerations, is considered better than existing products by all users (for all uses); hence the idea that products can be ranked according to a 'quality ladder' (Grossman and Helpman, 1993,Chap. 4).

The importance of this distinction derives from the differences in market dynamics that are associated with the two types of innovation. In particular, horizontal innovation generally results in the creation of new product groups that can coexist with older product groups.

Vertical innovation, on the other hand, is generally associated with a process whereby new and better products displace older obsolete products from the market. In markets subject to vertical differentiation, a firm (or more accurately a product) that does not follow the pace of technological advance may be driven out of the market. In other words, in order to survive, a firm needs some basic capabilities, and the need to improve these capabilities over time as its competitors improve theirs (hence the idea that a rising 'quality window' exists, outside which firms cannot survive in the market). This economic process can guide on the nature of market dynamics that may affect a particular industry.

\section{Step-Wise Innovation versus Incremental Innovation}

Step-wise innovation involves a relatively substantial degree of novelty, e.g. a new product or production process that is substantially different and/or better than older products. By contrast, incremental innovation is characterized by minor cumulative changes to products or production processes.

The extent to which an innovation is novel may be an important factor in assessing whether incumbent firms have an advantage over potential entrants or vice versa. In fact, industrial organization models suggest that incumbent firms may have different incentives to innovate than entrants. Similarly, given the difficulties that incumbent leading firms may have to deal with drastic changes as a form of of intrafirm systemic inertia, the opportunities for step-wise innovation may relatively favor incumbent firms.

\section{Intensity of Competition and Innovation}

There is little consensus about the relationship between intensity of competition (however defined) and innovation. At a general level, there is some evidence in favor of an inverse shape, indicating that innovation may be relatively less rapid at both very low and very high intensities of competition.

However, there is the question of at what point is more competition worse? This cannot be answered at the generic level, given the current level of understanding of these effects. Many of these problems derive from the difficulties involved in understanding the link between product market competition and innovation. This issue is best addressed on a case-by-case basis.

\section{Firms' heterogeneity and capabilities}

Prevailing models of dynamic competition deal essentially with firms' incentives to innovate. Not much attention is paid by theories rooted in the neoclassical tradition to the resources that firms need to innovate, nor to the importance that firms' heterogeneity may have in affecting market dynamics. For instance, whether a market is prone to dynamic persistence of monopoly depends not only on the incentives to innovate that an incumbent firm has compared to a potential entrant, but also on their relative capabilities, which may not be immediately ostensible. 
The notion of firms' capabilities seems crucial to the understanding of market dynamics driven by innovative activities. In fact, we believe that it is by emphasizing the importance and nature of different firms' capabilities that evolutionary theories of innovation are most useful to apply.

Capabilities to innovate may depend on a number of factors: having (the ability) to access external sources of knowledge (e.g. scientific knowledge); having access to some tacit knowledge which is not transferable (perhaps because embodied in organizational routines); and having access to some specific complementary resources, e.g. specific input factors.

\section{Tacit knowledge}

The capability of a firm to innovate in particular areas will be affected by the extent of tacit knowledge supporting its innovative activity, and whether the firm has access to this knowledge (e.g. acquired through a process of learning-by-doing).

Tacit knowledge cannot be codified, transferred or imitated by external parties but is rather embodied in routines and skills of the firm. The term 'tacit knowledge' is used to encapsulate the idea of knowledge that is found to be useful (e.g. in an organizational routine or a skill) without being articulate, and therefore without being directly transferable (e.g. sold as information).

\section{INNOVATION AND LEARNING}

Innovation is associated with the learning process that results from the combination of both internal and external sources. It is useful to assess the extent to which sources of learning associated with innovation observed in the relevant market are external or internal to the firms in the market. As for practical purposes, we shall draw the distinction between:

1. markets based on invention, where the sources of learning are essentially internal and dynamic change is largely due to firms' own creative and inventive actions, possibly in the form of $\mathrm{R} \& \mathrm{D}$, or other sunk costs, investments or activities that lead to learning-bydoing,

2. Markets based on adoption, where innovation derives largely from external sources such as suppliers or other sectors in the economy (research organizations).

We should accept that this distinction is not absolute. Each innovation, in every market, would generally involve both elements of invention and adoption. Few innovative improvements will be genuinely unique to the innovating firm since they will always involve a degree of imitation and adoption from observation of the world outside of the firm. Any invention will draw to some extent on past innovations and knowledge. Conversely, even where a firm seems to be directly adopting innovations associated with inventive effort by other organizations, it will need to adapt these to its own characteristics and circumstances, which requires an element of invention. Even where innovation is largely driven by inventive improvements in the services provided by suppliers, firms using such services may need some creative effort to incorporate these into their production processes and products. This view is underlined by comments from Nelson (1996, p.244) following an extensive cross-country empirical study on innovation: "...the bulk of the effort innovation needs to be done by the firms themselves. While they may draw on outside developments, significant internal effort and skill is needed to complement and implement these."

Nonetheless, we can conceive of distinguishing the extent to which the innovation associated with supply of a future market is adoptive rather than innovative, even if both elements must be present to some degree. 
In markets based on invention, a further distinction can be drawn on the basis of the sources of internal learning which has implications for the nature of the knowledge bases:

i. $\quad$ R\&D based markets. R\&D is in many markets an important source of learning at the firm level both because it is associated with the production of new knowledge and because it allows the firm to access externally available knowledge.

ii. In some other markets innovation is mainly driven by learning-by-doing. Learning results in a form of knowledge that is likely to be tacit, specific and relatively immobile, which implies that a firm would have to go down the learning curve without possibly relying on major knowledge spillovers from other firms .

An example of an adoptive market is a supplier-driven market where innovations are largely exogenous to the market and mainly embodied in equipment and components bought from other sectors. In these markets the process of innovation is essentially the process of diffusion of state-of-the-art capital goods and innovative intermediate inputs. The capability to supply in these markets requires essentially access to suppliers at terms that do not put it at a disadvantage relative to incumbent firms. The term 'suppliers' needs to be interpreted broadly to include both supplier firms and also organizations such as universities.

All else equal, innovation associated with adoption will yield a larger set of firms with capability to supply the future market which derives from that innovation.

\section{Knowledge Base}

Another important determinant of the ability to supply through innovation is the nature of the knowledge base on which innovation in the market is mainly built.

Dosi (1988) defines the notion of 'knowledge base' as:

“...the set of information inputs, knowledge, and capabilities that inventors draw on when looking for innovative solutions".

For instance, Dosi suggests that in the case of microelectronics there are three major and complementary forms of knowledge: advances in solid-state physics; knowledge related to the construction of semiconductor manufacturing and testing equipment; and programming logics.

Technologies may differ in terms of the degrees of 'publicness' and 'universality' versus tacitness and specificity of their knowledge bases (Winter 1987). The tacit/codified nature of the knowledge base can be considered very important to determine the firms' capability to supply in a future product market.

All else equal, innovation associated with a codified, rather than tacit, knowledge base will yield a larger set of firms with capability to supply the future market which derives from that innovation.

\section{Similarly for the general/specific nature of the knowledge base}

All else equal, innovation associated with a general, rather than specific, knowledge base will yield a far larger set of firms with capability to supply the future market which derives from that innovation.

This latter consideration suggests that an important element to consider is whether the knowledge base underlying innovation in the relevant markets is shared with other sectors in the economy. It may be the case that different sectors are similar in terms of the underlying 
knowledge base, so that a firm that operates in one would find it relatively easy to supply in the other market, with a similar knowledge base.

\section{ADJUNCT MARKETS}

An adjunct market can be defined, for current purposes, as one where the existence of demand in the market is dependent entirely on consumption in a related, but separate, relevant market (the primary market).

A commonly cited example is that of printers and compatible ink-refill cartridges, where demand for the latter is derived entirely from consumption of the former. In this case, the scope for competition in innovation directed to refill cartridges will be affected by whether cartridge manufacturers can interact successfully with the printers market.

A less obvious example is markets concerned with advertising (the supply of advertising space). In most cases, the existence of the advertising market is dependent on consumption in a related content market (be that the supply of television services, the supply of newspapers, magazines, or the supply of content on the Internet). Analysis of competition in the innovative activity related to entry in the advertising markets must pay attention to the need for the firm to simultaneously operate successfully in the content markets. So the relationship between advertising relevant markets and content relevant markets falls under the category of adjunct markets.

Of particular importance is where a competitive primary market is associated with an adjunct market in which there is monopoly. Thus firms compete in a broad primary market and each achieves monopoly supply in a narrow adjunct market (printers and refill cartridges). In such cases we may expect firms to use any marginal increase in profits realized in the secondary market to fund a decrease in price in the competitive primary market and thereby improve their relative position against competitors. Moreover, we would expect there to be checks against certain types of anti-competitive behavior in the monopoly linked markets due to the transfer of competitive effects from the primary market.

Thus in adjunct market cases, the effect may be such that innovative activity related to the secondary markets will depend on the ability of the firm to enter the primary market successfully; or the ability of the firm to 'gain access' to the necessary links between the primary and linked markets.

\section{Network Effects}

There seem to be clear similarities between adjunct markets and network effects, but the former is defined above as where consumption of a product in one market creates demand in another, while network effects are more related to how consumption of a product in one market increases demand for either (i) that product or (ii) a product in a different market that in turn may lead to increases in demand for the original product (see Gottinger (2003) for discussion of network effects).

Again network effects have important implications for the capability of firms to supply future markets associated with innovation. Supply to the future market will require a strategy for interacting with the network effects in such a way as to make the entry successful and sustain a position in the market. In particular, network effects can generate important benefits for incumbent technologies and thus create inter-temporal links between current and future markets, as discussed in the following section. 


\section{Intertemporal Dimension}

Assessment of the capability to supply a future market may hinge dramatically on analysis of the 'intertemporal links' that exist between suppliers in a current market and potential suppliers to a future market. At a basic level there exist links over time between relevant markets wherever a firm's supply on a current market affects its capability to supply a future market, either positively or negatively. In many cases this is trivial, but cases may exist where the cumulative effects are so strong as to be the driving force of which firm will succeed in a distinct future market.

In particular, we would be interested in whether conditions are such that it is necessary to be competing strongly in a current market in order to have the capability to supply the future market, or whether the innovation associated with the supply of the future market is so drastic that entrants and incumbents have a similar capability to supply the future market. These factors will be key drivers of whether there is persistence of market power.

The links between different markets over time may be a critical factor in determining the ability of the process of competition to select the 'right' innovations from a new variety of products in a future market. If there are strong factors favoring persistence of leaders in current markets into future markets, this may undermine the benefits of competition in the innovation itself.

In many cases incumbency advantage should not be seen as detrimental. Consumers are likely to value similarities between current and future products, while producers will be able to make efficiency savings from use of similar production processes and reputation effects between current and future markets. But, to the extent that competition is possible in innovation and the supply of the future generation of products and technologies, this may bring sufficient benefits to warrant protection. The discussion of high profile competition cases shows (Hahn,2003), even if there are benefits in only one operating system dominating current markets (e.g. due to economies of scale and customer familiarity) this does not preclude the benefits of competition to be the dominant supplier of 'next generation' operating systems.

Finally and very importantly, it should be possible to distinguish cases where any positive relationship between current and future markets is due to less-strategic characteristics of the market, such as its cost structure and nature of demand and the type of innovation associated with it; or the opportunity it provides incumbent firms to behave anti-competitively, in particular as regards competition in innovation.

\section{Supply and Demand Side Links}

The standard link on the supply side from one market to another comes simply from the fact that the production processes used to supply a current relevant market may be capable of use to supply a future market, even if the nature of the product supplied changes over time. This arises in particular where the same sunk costs are incurred to supply both current and future markets and therefore incumbents in the current market have an advantage to the extent that they have already incurred the costs.

In addition to standard production processes links, where the knowledge associated with the innovation into the future market is largely tacit, or non-imitable in another way, incumbents are in possession of a further advantage derived from the nature of the innovation itself. Conversely, where the innovation is more drastic and does not particularly build on tacit knowledge embodied in the supply of previous products we would not expect a strong 
advantage for current incumbents. Therefore analysis of the nature and source of innovation will feed into this analysis of inter-temporal effects.

When considering inter-temporal relationships, it is beneficial to understand that network effects can work through mechanisms based on both actual events and expectations. Most commonly, network effects are due to consumers at one period in time taking into account past consumption either by themselves or other consumers, when making their current purchase decision.

But network effects can also be generated by expectations. Consumers may form today expectations of what technologies and services other consumers will consume, and in turn lean towards products associated with this in order to benefit from network effects. Where this occurs firms are likely to be active in advertising and marketing their products to create an impression of high future consumption on current consumers, and to signal staying power in the market.

A further but perhaps less obvious type of (direct) network effect is economies of learning. Where consumers must invest in obtaining some specific knowledge and skills that facilitates consumption of the product, network effects may set in between products.

In the case of direct network effects, the relevant link between markets is actually directly between the current relevant market and the future market. In essence, network effects mean that on the demand-side the future market is linked to the current relevant market by the fact that consumption of a product in the current relevant market enhances demand for that product (or its descendant) in the future market.

In the case of indirect network effects, the relevant link between markets is indirect between the current relevant market and the future market, because it exists through a horizontally related market.

Such relationships are therefore important in a later stage, and discussed further below. The following table suggests possibilities for inter-temporal links between markets that may put firms which currently supply a related current market at a significant competitive advantage in the capability to supply the future market than firms that do not.

\section{References}

Aghion, P. and R.Giffith (2005) Competition and Growth, Cambridge, Ma. MIT Press

Arrow, K.J. (1962),"Economic Welfare and the Allocation of Resources for Invention", in the Rate and Direction of Inventive Activity: Economic and Social Factors, Princeton: Princeton Univ. Press, 609-625

Brenner, R. ((1987), Rivalry in Business, Science, Among Nations, Cambridge: Cambridge Univ. Press

Cohen,W.M. and R.C. Levin (1989),“Empirical Studies of Innovation and Market Structure“, in Handbook of Industrial Organization, Vol. II, R. Schmalensee and R.D.Willig, eds, Amsterdam:North Holland

Dosi, C. (1988), “Sources, Procedures and Macroeconomic Effects of Innovation”,

Journal of Economic Literature 26(3), 1120-1171

Easley, D. and J.Kleinberg (2010), Networks, Crowds and Markets, Cambridge: Cambridge Univ. Press

Evans, D., Hagiu, A. and R. Schmalensee (2006), Invisible Engines, How Software Platforms Drive Innovation and Transform Industries, Cambridge, Ma. MIT Press 
Fisher, F.M, McGowan, J.J. and J.E. Greenwood (1983), Folded, Spindled, and Mutilated, Economic Analysis and U.S. v. IBM, Cambridge, Ma. MIT Press

Gottinger, H.W. (2003), Economies of Network Industries, London: Routledge

Gottinger, H.W. (2006), Innovation, Technology and Hypercompetition, London: Routledge

Grossman, G.M. and E. Helpman (1993), Innovation and Growth in the Global Economy, Cambridge, and Ma: MIT Press

Hahn, R.W., ed. (2003), High-Stakes Antitrust, The Last Hurrah?, Washington,D.C.: AEI-Brookings Joint Center for Regulatory Studies

Jacquemin, A. (1987), the New Industrial Organization, Market Forces and Strategic Behavior, Cambridge, Ma. MIT Press

Kucher, H. (2009), Hidden Champions of the 21st Century, New York: Springer

Lerner, J. (2012), the Architecture of Innovation, the Economics of Creative Organizations, Boston: Harvard Business Review Press

Nelson, R.R. (1996),"The Sources of Growth", Chap.10 in National Innovation Systems, Cambridge, Ma. Harvard Univ. Press, 274-301

Radner, R. (1986), “The Internal Economy of Large Firms”, Annual Conference of the Royal Economic Society, Supplement to the Economic Journal 96, 1-22

Scherer, F.M. (1984), Innovation and Growth, Schumpeterian Perspectives, Cambridge, Ma. MIT Press

Scherer, F.M. (1992), International High Technology Competition, Cambridge, Ma. Harvard Univ. Press

Schumpeter, J.A. (1942), Capitalism, Socialism and Democracy. New York: Harper

Stigler, G. (1968), the Organization of Industry, Chicago: Univ. of Chicago Press

Tirole, J. (1988), the Theory of Industrial Organization, Cambridge, Ma. MIT Press 